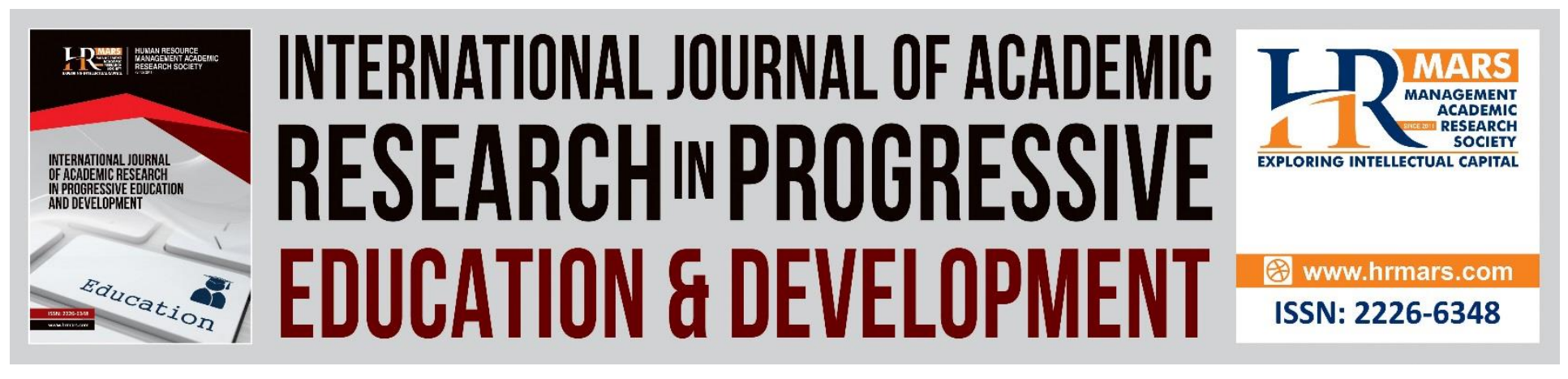

\title{
Comparing the Value of Control with Characteristic of Prediction Conveyed in Mathematics Textbooks in Malaysia and Australia
}

Mohd Uzi Dollah, Mohd Nazir Md Zabit, Tirzah Zubeidah Zachariah Omar

To Link this Article: http://dx.doi.org/10.6007/IJARPED/v7-i4/5332 DOI: $10.6007 /$ IJARPED/v7-i4/5332

Received: 28 Oct 2018, Revised: 30 Nov 2018, Accepted: 18 Dec 2019

Published Online: 10 Jan 2019

In-Text Citation: (Dollah, Zabit, \& Omar, 2018)

To Cite this Article: Dollah, M. U., Zabit, M. N. M., \& Omar, T. Z. Z. (2018). Comparing the Value of Control with Characteristic of Prediction Conveyed in Mathematics Textbooks in Malaysia and Australia. International Journal of Academic Research in Progressive Education and Development, 7(4), 387-396.

Copyright: (C) 2018 The Author(s)

Published by Human Resource Management Academic Research Society (www.hrmars.com)

This article is published under the Creative Commons Attribution (CC BY 4.0) license. Anyone may reproduce, distribute, translate and create derivative works of this article (for both commercial and non-commercial purposes), subject to full attribution to the original publication and authors. The full terms of this license may be seen at: http://creativecommons.org/licences/by/4.0/legalcode

Vol. 7, No. 4, 2018, Pg. 387 - 396

http://hrmars.com/index.php/pages/detail/IJARPED

JOURNAL HOMEPAGE

Full Terms \& Conditions of access and use can be found at http://hrmars.com/index.php/pages/detail/publication-ethics 


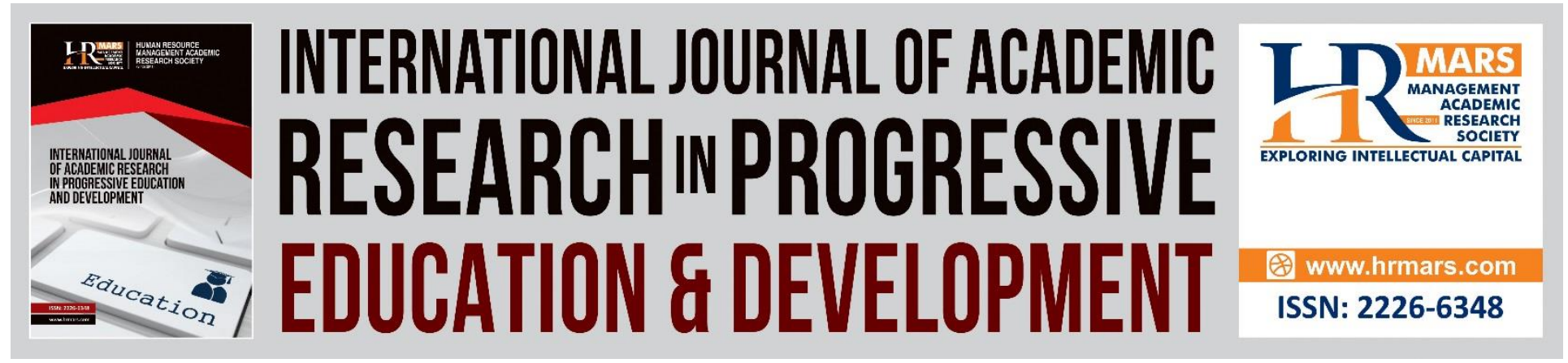

\title{
Comparing the Value of Control with Characteristic of Prediction Conveyed in Mathematics Textbooks in Malaysia and Australia
}

\author{
Mohd Uzi Dollah ${ }^{1}$ Mohd Nazir Md Zabit ${ }^{1}$, Tirzah Zubeidah \\ Zachariah Omar' \\ Universiti Pendidikan Sultan Idris, Malaysia, Universiti Selangor (UNISEL), Malaysia
}

\begin{abstract}
This study aimed to compare the value of control with characteristics of prediction conveyed in Year 10 secondary school mathematics textbooks from Victoria, Australia and Malaysia. A mathematical textbook was analyzed from each country, namely the TVA Math textbook from Australia and TMA Math textbook from Malaysia. Two chapters were selected for analysis from both textbooks with two equivalent chapters, namely Linear Equation and Trigonometric. Content analysis was used to analyze the data. In general, the TVA Math textbook conveyed the value of control with the characteristics of prediction more significantly, compared to the TMA Math textbook. The analysis of both of the Math textbooks show that, the value of control with characteristics of prediction was conveyed through three situations, namely learning objective, note and problem solving. The recommendation was that both textbooks, especially the Malaysian mathematics textbook, should be given more opportunities to instill more mathematical tasks related to the value of control, specifically the characteristic of prediction. Hence the mathematical textbooks could become a more comprehensive learning resources, if it focused not only on the cognitive aspect, but also on the affective aspects, particularly the value of control.
\end{abstract}

Keywords: The Value of Control, Prediction, Cognitive, Affective.

\section{Introduction}

Textbooks are one of the main sources of mathematical knowledge to students. Through textbooks, the students are not only exposed to the cognitive domain but also the affective domain (Dollah \& Widjaja, 2018). There are quite a number of studies focusing on cognitive domains, but not many have focused on effective domains (Seah \& Bishop, 2000; Cao, Seah and Bishop, 2006; Dollah \& Widjaja, 2018). A few previous studies have focused on effective domains, particularly the application of value through textbooks, such as Seah and Bishop (2000) and Cao, Seah, and Bishop (2006). The latest study by Dollah and Widjaja (2018) looked at the comparison 
INTERNATIONAL JOURNAL OF ACADEMIC RESEARCH IN PROGRESSIVE EDUCATION AND

DEVELOPMENT

Vol. 7, No. 4, 2018, E-ISSN: 2226-6348 ๑ 2018 HRMARS

of applying mathematical value (i.e value of progress) in textbooks from Australia and Malaysia. In general, the value of rationalism was conveyed through both textbooks (i.e Australian and Malaysian mathematical textbooks). However, the inculcation of the value of rationalism was moderate for some characteristics such as reason, explanation, hypothetical reasoning, abstraction, logical thinking and theorem.

\section{Literature Review}

Mathematical value is an affective quality related to mathematical properties, which relates to how mathematical disciplines are developed in various cultures (Bishop, 1988; Dollah \& Widjaja, 2018). Mathematical values are related to the epistemological aspect of mathematics (Dollah, 2007). Generally, the mathematical values can be categorized into three, namely general education values, mathematics education values and mathematical values (Bishop, 2008). The general education values are qualities related to the moral values and norms of a particular society. The mathematics education values are qualities imbedded in a particular classroom, textbooks or any other teaching and learning resources. The mathematical value is related to the epistemology of mathematics as a discipline (Bishop, 1988; Dollah \& Widjaja, 2018).

According to Bishop (2008), the value of control is one category of the mathematical value, besides five others which are rationalism, objectivism, progress, openness and mysteries. One characteristic of the value of control is prediction, while five others are prediction, mastery over environment, knowing, rules, security and power (Bishop, 2008). Prediction is a difficult skill for many people, especially students (McAleer, 2017a). Prediction can be characterized into two, i.e predict and estimate. Prediction is concerned with guessing the evolution of certain phenomena or situation (Cesa-Bianchi \& Logosi, 2006). In the context of solving mathematical problems, to predict means to have an expectation prior to a specific action taken to overcome the problems (Lim, Buendía, Kim, Cordero, \& Kasmer, 2010).

Estimation is a process of thinking that involves an educated guess about a measure or a quantity of the outcome of a mathematical task (New Jersey Mathematics Curriculum, n.d.). The New Jersey Mathematics Curriculum (n.d) highlights estimation strategies as a new and important domain in the curriculum. However, teachers lack emphasis on teaching involving estimation because they focus too much on preparing students for examination; as a result, fun and engaging activities do not appear in mathematical teaching (McAleer, 2017b).

The ability in predicting or estimating answer to mathematical problems among students is considered as a very important task to be achieved. Good estimators tend to have a strong selfconcept about math, and believe that their success in estimation during mathematical learning depends on their ability rather than just effort (Bergeson, 2000). However, contents of mathematics related to prediction have received less attention in teaching and learning mathematics, compared to other aspects of reasoning, such as reasoning and generalization (Lim, Buendía, Kim, Cordero, \& Kasmer, 2010).

Teaching prediction in mathematics is essential for students to understand the mathematical concepts meaningfully, rather than simply memorizing mathematical knowledge as unconnected 
DEVELOPMENT

Vol. 7, No. 4, 2018, E-ISSN: 2226-6348 @ 2018 HRMARS

facts and rules (Tsao \& Pan, 2013). While seeking answers tends to strengthen instrumental understanding, predicting answers can promote relational understanding of mathematical concepts among students (Lim, Buendía, Kim, Cordero \& Kasmer, 2010). According to Lim, Buendía, Kim, Cordero and Kasmer (2010), learning to make prediction will encourage the students to activate previous knowledge and to articulate their understanding of the phenomenon being investigated.

\section{Problem Statement}

The teaching and learning through mathematics tasks involve prediction is explained through many studies. However, those which involve the analysis of mathematics textbooks are very limited. The role of mathematics tasks involving prediction is very important in mathematics teaching and leaching (Kim \& Kasmer, 2007; Lim, Kim, Cordero, Buendía, \& Kasmer, 2007). According to Kim and Kasmer (2007), prediction is one type of reasoning that can lead the students to be able to make generalization of concepts; a product of a generalization is known as prediction. Activities that allow students to make predictions can be used to uncover knowledge, schemes, misunderstandings, and intuition of students in mathematical learning (Lim, Kim, Cordero, Buendía, \& Kasmer, 2007).

Prediction plays a very important role in learning such as provoking students' prior knowledge, motivating students' interest, looking for alternative perspective in problem solving, establishing a connection between concepts and also as a tool to evaluate student thought (Kim \& Kasmer, 2007). Lim, Kim, Cordero, Buendía, \& Kasmer (2007) add that the ability of the students to make predictions do not happen arbitrarily, but it is based on their judgment to represent a more likely event based on certain characteristics of the population. For example, in the case of predicting a sequence of six children in a family, GBGBBG is more likely than GBGBBG although the probability for both sequences is equally likely to happen.

The mathematics textbook is a source of affective domain beside teachers for students. Therefore, the contents of the textbook and the ways they are presented could play very important roles in promoting the value of control, specifically the characteristics of prediction.

\section{Method}

This study aimed to compare the value of control with the characteristics of prediction conveyed through mathematical textbooks from two different countries, Australia (Victoria) and Malaysia. Specifically, this research focused on comparing and understanding how the value of control, namely the characteristics of prediction were conveyed through both textbooks.

The selection of the both textbooks utilized convenient sampling. The mathematical textbook from Australia (Victoria) was referred to as TVA Math (pseudonym) textbook and the mathematical textbook from Malaysia was referred to as TMA Math (pseudonym) textbook. The analysis involved one Year 10 secondary school mathematics textbook from each country. Both textbooks contained 11 chapters. However, only 6 out of 11 chapters from both textbooks contained almost similar content. Two equivalent chapters that contain almost similar content 
INTERNATIONAL JOURNAL OF ACADEMIC RESEARCH IN PROGRESSIVE EDUCATION AND

DEVELOPMENT

Vol. 7, No. 4, 2018, E-ISSN: 2226-6348 @ 2018 HRMARS

from each textbook were selected through purposive sampling. The two chapters selected are shown in Table 1.

Table 1

The chapters from TVA Math textbook and TMA Math textbook

\begin{tabular}{lll}
\hline & TVA Math textbook (Victoria, & TMA Math textbook (Malaysia) \\
& Australia) & \\
\hline 1 & Chapter 2: Linear equation & Chapter 5: Linear equation \\
2 & Chapter 9: Trigonometry & Chapter 9: Trigonometry II \\
\hline
\end{tabular}

The content analysis approaches had been conducted to analyze the data from textbooks which focused on the value of control with the characteristic of prediction conveyed in both textbooks. The analysis of the data was based on one characteristic of the value of control, namely the prediction (Bishop, 2008). The validity of the research was achieved through experts' opinion. The reliability of the analysis was achieved through experts' opinion and peers checking. Two experts were used in this research and both of them were lecturers in the field of mathematics education.

\section{Findings}

Generally, the value of control with characteristic of prediction was conveyed more significantly in the TVA Math textbook, compared to the TMA Math textbook. The value of control was conveyed in the mathematics textbooks through the use of words such as 'predict' and 'estimate' (Table 2). There were seven cases involving prediction and three cases involving estimation in the TVA Math textbook, compared to only one case involving estimation in the TMA Math textbook.

Table 2

The value of control with characteristics of prediction and estimation conveyed through the chapters of "Linear equations" and "Trigonometry" of the TVA Math textbook and the TMA Maths textbook.

\begin{tabular}{lllllll}
\hline & \multicolumn{3}{l}{ The TVA Math textbook } & \multicolumn{3}{l}{ The TMA Math textbook } \\
\cline { 2 - 7 } & $\begin{array}{l}\text { Learning } \\
\text { objective } \\
\text { (cases) }\end{array}$ & $\begin{array}{l}\text { Note } \\
\text { (cases) }\end{array}$ & $\begin{array}{l}\text { Mathematic } \\
\text { s problems } \\
\text { (cases) }\end{array}$ & $\begin{array}{l}\text { Learning } \\
\text { objective } \\
\text { (cases) }\end{array}$ & $\begin{array}{l}\text { Note } \\
\text { (cases) }\end{array}$ & $\begin{array}{l}\text { Mathematic } \\
\text { s problems } \\
\text { (cases) }\end{array}$ \\
\hline Predict & 2 & 2 & 3 & - & - & - \\
\hline Estimate & - & 3 & - & 1 & - \\
\hline
\end{tabular}

\section{Predict}

The tasks to predict were clearly observed in TVA Maths textbook, but did not appear in TMA Math textbook. The tasks from the TVA Math textbook appeared in three ways, namely the learning objective, note and mathematics problems. 
INTERNATIONAL JOURNAL OF ACADEMIC RESEARCH IN PROGRESSIVE EDUCATION AND

DEVELOPMENT

Vol. 7, No. 4, 2018, E-ISSN: 2226-6348 @ 2018 HRMARS

Prediction in learning objective: There were two cases involving the task to predict from the TVA Math textbook in the learning objective. One example could be seen when the text from the TVA Math Textbook described about objective of the chapter, which is to make prediction, as seen below:

"....In this chapter, you will investigate some predictions about Mathematical modelling is at the heart of trying to predict what may happen and when.... In this chapter, you will investigate some predictions about our changing planet."

(TVA/LE/01)

Prediction in note: There were two cases involving notes to highlight tasks to predict. The first task involving a note was used as an introduction of a topic from the chapter 'Linear equations' in the TVA Math Textbook. It showed the inculcation of the value of control with the characteristics of prediction through a discussion about the history of how the mathematical formula was discovered. In the TVA Math textbook, the formula was used to predict the temperature of a place based on the chirping sound of a cricket (TVA/LE/O2):

In 1898 an American scientist, A. E. Dolbear, noted that the temperature could be reasonably predicted ... He developed a linear equation based on his research:

$\boldsymbol{T}=\mathbf{5 0}+\frac{N-40}{4}$

where $N$ is the number .... (TVA/LE/ O2)

Another example of the value of control with the characteristics of prediction can be seen in the text of the chapter 'Trigonometry' of TVA Math textbook. The text describes the history of Milutin Milankovic (1879-1958) who made a prediction about the climate of the world based on the cyclical pattern:

He predicted that 12000 years from now the northern hemisphere will experience summer in December and winter in June ..., its current alignment. (TVA/TR/O3)

Prediction in problem solving: There were three cases involving prediction in problem solving from the TVA Math textbook. The first example of the mathematics problem was to predict the performance of female and male swimmers in the Olympic 100 meters freestyle event using the concept of straight lines or linear equations (TVA/LE/03).

"Predict the greatest number of points of intersection made when 10 straight lines intersect." (TVA/LE/O4).

Another example of the mathematics problem in the TVA Math textbook was from the subtopic 'Rich tasks' that involved the application of 'Linear equations' in everyday life. It involved the text asking students to predict the temperature of the world in 2030. The excerpt from the text of 'Rich tasks' is as the following: "Your task is to model increasing temperature and make a linear model to predict the temperature in the year 2030, ...." (TVA/LE/O4). The inculcation of the value 
INTERNATIONAL JOURNAL OF ACADEMIC RESEARCH IN PROGRESSIVE EDUCATION AND

DEVELOPMENT

Vol. 7, No. 4, 2018, E-ISSN: 2226-6348 @ 2018 HRMARS

of control with the characteristic of prediction was highlighted further as seen in the excerpt: "Mathematicians can develop simple models to help predict the future." (TVA/LE/O5)

\section{Estimate}

The value of control with the characteristic of prediction could be seen through the use of the word estimate. There were three cases involving the word estimate from the TVA Math Textbook, but only one case from the TMA Math textbook.

Two cases were identified from the chapter 'Linear equations' of the TVA Math textbook. Both of the cases as seen in the excerpts (TVA/LE/06) and (TVA/LE/07) described the predicted time for two swimmers to catch up using the concept of linear equation.

"With a partner, use the graph below to estimate the year in which the women's time will catch up to the men's...." (TVA/LE/O6).

"... Extend the lines and estimate the year when men and women will have the same times." (TVA/LE/O7).

The value of control with the characteristic of prediction in the chapter "Trigonometry" was also identified through the use of the word 'estimate' in the mathematics problem (TVA/TR/08):

A hiker is hiking up ..... After 160 steps she estimates that her eyes are level with ...

.... What is the effect on her estimate of the size of the tree if ...? (TVA/TR/08)

However, there was only one case involving the value of control with the characteristic of prediction was identified in the TMA Math textbook. Below is the text about estimating the height of Mount Everest as in the excerpt (TMA/TR/01).

"...by using satellite and latest knowledge about geometry, the Everest mountain is estimated at 8848 meters. ..." (TMA/TR/01).

\section{Discussion}

Generally, the value of control with characteristics of prediction was conveyed more significantly in the TVA Math textbook. However, the value of control with characteristics of prediction was conveyed in less noticeable way in the TMA Math textbook. The analysis indicated that the value of control with the characteristics of prediction conveyed in both textbooks could be divided into three situations: through the learning objective, note and mathematics problem.

Only the Australian math textbook highlighted the prediction through the learning objective. This could indicate that only the Australian mathematics textbook had clear intentions in considering the value of control with the characteristics of prediction as mathematical tasks. However, the Malaysian mathematics textbook did not show clear intentions in considering the value of control with the characteristics of prediction as mathematical tasks. This was not in line with one of the 
DEVELOPMENT

Vol. 7, No. 4, 2018, E-ISSN: 2226-6348 @ 2018 HRMARS

focuses of learning mathematics in Malaysia, which is to develop ability to conjecture among students (Ministry of Education of Malaysia, 2012).

Most of the value of control with the characteristic of prediction was conveyed in the Australian textbook through note and mathematical problem. It could show that the Australian textbook had put in more opportunities to inculcate the value of control with the characteristics of prediction through mathematical tasks and problem solving. By instilling prediction in the mathematical tasks and mathematics problem, this would help the students to develop mathematical thinking, especially in promoting reasoning and generalization (Kim and Kasmer, 2007).

This finding also showed that TVA Math textbook textbooks had more specific textual content in order to make the students capable of thinking more openly and critically, especially towards building the ability to predict what was likely to happen in the future. The tasks in the textbooks that expose students to make prediction will promote them to uncover knowledge, schemes, misunderstanding and intuition in mathematics learning (Lim, Kim, Cordero, Buendía, \& Kasmer, 2007)

On the other hand, TMA Math textbooks appeared to focus less on inculcating the value of control with the characteristics of prediction. This implied that the TMA Math textbooks were less likely to encourage students to build relationships between previous knowledge with the situation that they may have in the future and this also may make them difficult to argue about any phenomenon (Lim, Buendía, Kim, Cordero, \& Kasmer, 2010).

This problem will be more problematic in the process of learning as Lim, Buendía, Kim, Cordero and Kasmer (2010) also highlighted that the mathematical content of prediction was less emphasized in the teaching and learning process than other aspects such as reasoning and generalizations. Giving low emphasis on the application of the value of control, particularly relating to the characteristic of prediction, will limit this book from achieving the goal of promoting reasoning and making generalization among students (Kim and Kasmer, 2007). According to McAleer (2017b), less emphasis on mathematical learning through predictive activity will make the teaching less meaningful and less interesting.

\section{Conclusion}

This research focused on comparing the value of control with the characteristic of prediction conveyed in the Mathematics Textbooks in Australia (TVA Math textbook) and Malaysia (TMA Math textbook). Generally, the value of control with the characteristic of prediction was conveyed in the Australian mathematics textbook (TVA Math textbook) more significantly compared to the Malaysian mathematics textbook (TMA Math textbook). There should be more opportunities in the Malaysian Math textbook to instill more mathematical tasks related to the value of control, specifically the characteristic of prediction. This will ensure the mathematical textbooks can become a more comprehensive learning resource as the contents should not only focus on the cognitive domains, but also on the affective domains, particularly the value of control. 
INTERNATIONAL JOURNAL OF ACADEMIC RESEARCH IN PROGRESSIVE EDUCATION AND

DEVELOPMENT

Vol. 7, No. 4, 2018, E-ISSN: $2226-6348 @ 2018$ HRMARS

\section{References}

Bergeson, T. (2000). Teaching and Learning Mathematics. State Superintendent of Public Instruction, PO Box 47200, Olympia, WA 98504-7200. Retrieved July 19, 2000 from http://www.k12.wa.us/research/pubdocs/pdf/MathBook.pdf

Bishop, A. J. (1988). Mathematics education in its culture context. Educational Studies in Mathematics, 19, 179-191.

Bishop, A. J. (2008). Values in Mathematics and Science Education: similarities and differences. The Montana Mathematics Enthusiast, ISSN 1551-3440, Vol. 5, no.1, pp. 47-58

Cao, Z. J., Seah, W. T., \& Bishop, A. J. (2006). A comparison of mathematical values conveyed in mathematics textbooks in China and Australia. In F. K. S. Leung, K-D. Graf, \& F. J. LopezReal (Eds.), Mathematics Education in Different Cultural Traditions - A Comparative Study of East Asia and the West (pp. 483 - 493). New York NY USA: Springer.

Cesa-Bianchi, N. \& Logosi, G., (2006). Prediction, Learning, and Games. UK: Cambridge University Pres.

Dollah, M. U. (2007). Inculcation of the value in mathematics teaching of secondary school mathematics teachers: A case study (Penerapan nilai dalam pengajaran guru matematik sekolah menengah: Satu kajian kes). Unpublished Doctor of Philosophy Thesis. Pulau Pinang, Malaysia: Universiti Sains Malaysia.

Dollah, M. U. \& Widjaja, W. (2018). Comparing the Inculcation of the Value of Rationalism from the Australia and Malaysia Mathematics Textbooks. The Eurasia Proceedings of Educational \& Social Sciences (EPESS), 2018 Volume 9, Pages $261-268$. http://dergipark.gov.tr/download/article-file/532803

Kim, O. K., \& Kasmer, L. (2007). Prediction and mathematical reasoning. Proceedings of 2007 Hawaii International Conference on Education (pp. 3016-3034). Honolulu, HI.

Lim, K. H., Kim, O. K., Cordero, F., Buendía, G., \& Kasmer, L. (2007). Use of prediction in mathematics classroom. In Lamberg, T., \& Wiest, L. R. (Eds.), Proceedings of the Twentyninth Annual Meeting of the North American Chapter of the International Group for the Psychology of Mathematics Education, (pp. 1239-1248). Stateline, NV: University of Nevada, Reno.

Lim, K. H., Buendía, G., Kim, O. K., Cordero, F. \& Kasmer, L. (2010). The role of prediction in the teaching and learning of mathematics. International Journal of Mathematical Education in Science and Technology, 41:5, 595-608. Retrieved July 23, 2018 from https://www.tandfonline.com/doi/abs/10.1080/00207391003605239 
INTERNATIONAL JOURNAL OF ACADEMIC RESEARCH IN PROGRESSIVE EDUCATION AND

DEVELOPMENT

Vol. 7, No. 4, 2018, E-ISSN: 2226-6348 @ 2018 HRMARS

McAleer, J. (May 8, 2017a). Estimation Skills Sorely Lacking. National Council of Teachers of $\begin{array}{lllll}\text { Mathematics } & \text { (NCTM). } & \text { Retrieved } 23 & \text { Oct., } & 2018 \text { from }\end{array}$ https://www.nctm.org/Publications/Mathematics-Teaching-in-MiddleSchool/Blog/Estimation-Skills-Sorely-Lacking/

McAleer, J. (June 19, 2017b). There's Always Time for Estimating and Plenty of Resources. National Council of Teachers of Mathematics (NCTM). Retrieved 15 Oct., 2018 from https://www.nctm.org/Publications/Mathematics-Teaching-in-MiddleSchool/Blog/There_s-Always-Time-for-Estimating-and-Plenty-of-Resources/

Ministry of Education of Malaysia (2012). Integrated Curriculum for Secondary School, Curriculum Specification of Mathematics, Form 4. Putrajaya, Malaysia: Curriculum Development Division.

New Jersey Mathematics Curriculum (n.d.). Standard 10 - Estimation. Retrieved from https://www.state.nj.us/education/archive/frameworks/math/math8.pdf

Seah, W. T., \& Bishop, A. J. (2000, April 24-28). Values in mathematics textbooks: A view through two Australasian regions. Paper presented at the 81st Annual Meeting of the American Educational Research Association, New Orleans, LA.

TSAO, Y. L. \& PAN, T. R. (2013). The computational estimation and instructional perspectives of elementary school teachers. Journal of instructional pedagogies, VOL. 11, PG. $1-15$. RETRIEVED JULY 25, 2018 FROM HTTP://WWW.AABRI.COM/JIP.HTML 